\title{
MPs back increase to fund hadron collider
}

London. A parliamentary committee has supported Britain's particle physicists in their efforts to persuade the government to provide an extra $£ 60$ million (US\$92 million) towards the construction costs of the Large Hadron Collider (LHC) at the European Laboratory for Particle Physics (CERN) in Geneva. The funds would be provided over eight to ten years.

In a report on the Particle Physics and Astronomy Research Council published last week, the House of Commons Select Committee on Science and Technology says that there is a "good case" for a general increase in the science budget. And CERN should receive "adequate funding" to exploit the scientific opportunities offered by the LHC.

But the report's conclusions were not unanimous. Several committee members voted for an alternative conclusion which stated that it would be "quite unrealistic" to expect the Treasury to provide the money being requested. They said that the solution "has to be sought in a reappraisal and redeployment of the international efforts in research in particle physics".

The main argument of the report is that, in signing up with other CERN member states to the construction of the LHC at the end of 1994, Britain had agreed to a step that it can no longer properly afford at

current funding levels. The result is that the CERN subscription is becoming a subsidy of international science, "of very restricted value to British science".

A 25 per cent increase in the real costs of the subscription, at a time when the overall science budget is being kept level, will mean significant cuts in domestic expenditure on particle physics, including the development of LHC detectors.

The problems are caused largely by fluctuating exchange rates as the subscription is paid in Swiss francs. The committee says that, to

IMAGE

UNAVAILABLE FOR

COPYRIGHT REASONS avoid funding problems, such extra costs should be paid directly by the Treasury.

It also backs CERN's proposal that, if the govern-

Bray: timetable may need drastic revision. ment is not prepared to provide extra money towards the LHC costs directly, it should do so in the form of a loan (see Nature 381, 102; 1996). The research council's allocation would be reduced by an equivalent amount once the construction phase has ended, when CERN's annual budget is expect to fall by about 20 per cent.

The report has been welcomed by particle physicists, who have been expressing concern at the potential consequences of meeting the LHC costs out of CERN's commitment to their field - exacerbated by the research council's decision to put a cap on this commitment at its current level (see Nature 380, 576; 1996).

But enthusiasm for the select committee's conclusions has been tempered by the fact that three of the nine members present when the report was approved voted for a different set of recommendations. The main thrust of these is that the solution can only be found by discussions between the science ministers of the world's top seven industrialised nations.

The alternative amendment was drafted by Jeremy Bray (Labour, Motherwell South), a former shadow research minister. This warned that, without increased participation in CERN - "or the reconstruction of CERN on a global rather than a European basis" - the LHC timetable "may have to be rephased more drastically than has yet been considered".

"CERN is faced with the need for additional funds, and the only practical way of doing this is for CERN to get increased income from other sources," says Bray.

David Dickson

\section{Asbestos removal spells upheaval for Paris scientists}

Paris. A surprise announcement by Jacques Chirac, the French president, that "there will be no students left at [the university campus of] Jussieu by the end of 1997" because of asbestos contamination, was refuted a few days later by François Bayrou, the education minister.

Chirac's announcement in a national broadcast on Bastille Day (14 July) caught everybody by surprise, including Bayrou, who promptly appointed a 'Jussieu Mission' committee. But four days later, Bayrou announced that there would be no relocation of the 40,000 students and 10,000 staff from Europe's largest science campus.

Nevertheless, he promised that "there would be no limit to the state's financial commitment" to remove the asbestos, which is contaminating 220,000 square metres of teaching and research facilities at Jussieu.

The Jussieu Mission includes representatives of the campus's two universities, Paris VI and Paris VII, as well as the Institute of Physics of the Globe. It will present a detailed plan in the autumn for decontaminating the campus, which was built between 1965 and 1972 .

Faculty members had been alarmed at the prospect of relocating under such pressure. The presidents of the two universities, Jean Lemerle (Paris VI) and Jean-Pierre Dedonder (Paris VII), declared that "closing down Jussieu will spell the death of Paris VI and Paris VII and deal a severe blow to French scientific research".

Bayrou described Chirac's statement as a "boost" in dealing with a public health issue. But Ramez Sami, a mathematician who belongs to the Jussieu Anti-Asbestos Committee, a pressure group that has been active for 20 years, was less positive. "I don't understand why after so much resistance, such unrealistic and revolutionary measures are suddenly being proposed," he said.

The minister said priority will be given to emergency work to stop the release of asbestos dust. This will involve covering ceilings, walls and technical access areas with airtight plastic sheeting "before the end of 1996, or at the latest during the first quarter of 1997'. No specific budget has been allocated for this work, which is minor compared to removing the asbestos, estimated to cost of FF880 million to 1 billion (US\$176 million to US\$200 million).

A source at the Ministry of Education said that "the real cost will probably be closer to FF2 billion". She also doubted that the emergency phase of the project would be completed by 1997 .

It now appears that decontamination of the buildings will be done in stages, which will require only temporary shutdown of individual facilities while work is under way.

A senior member of the administration of the Institute of Physics of the Globe, Liliane Flabée, said that "we have already sealed off our ceilings and technical areas. This means we can lay no new cables or drill holes" because of the danger of releasing asbestos dust. "When the asbestos is removed," she predicted, "we will have to stop much of our research and we don't know for how long".

Research laboratories will be harder to decontaminate than teaching facilities. "Moving out massive equipment such as mass spectrometers, mainframe computers and computer networks is not going to be as easy as moving a desk and a PC," Flabée pointed out.

Michel Parigot, president of the AntiAsbestos Committee at Jussieu, says that Chirac's pledge to tackle the Jussieu issue had deterred him from taking legal action against the government for negligence. He estimates the Jussieu clean-up to be the largest operation of its kind in France.

Ronnie Amelan 